\title{
Decrease in late presentation for HIV care in Kinshasa, DRC, 2006-2020
}

\author{
Nadine Mayasi Ngongo ${ }^{1 *}$, Hippolyte Situakibanza Nani-Tuma ${ }^{1}$, Marcel Mbula Mambimbi ${ }^{1}$, \\ Murielle Longokolo Mashi', Ben Bepouka Izizag ${ }^{1}$, Faustin Kitetele Ndolumingu' ${ }^{1}$, Nathalie Maes², \\ Michel Moutschen ${ }^{3,4}$ and Gilles Darcis ${ }^{3 *}$ (D)
}

\begin{abstract}
Introduction: Late presentation for HIV care is a well-described issue for the success of ART outcomes and the cause of higher morbidity, mortality and further transmission. Monitoring the level of late presentation and understanding the factors associated with it would help to tailor screening and information strategies for better efficiency.

We performed a retrospective cohort study in Kinshasa, the capital of the DRC. The studied population included HIVpositive adults newly enrolled in HIV care between January 2006 and June 2020 at $25 \mathrm{HIV}$ urban care facilities. Patient information collected at presentation for HIV care included age, sex, WHO clinical stage and screening context. We used 2 definitions of late presentation: the WHO definition of advanced HIV disease (WHO stage 3/4 or CD4 cell count $<200$ cells $/ \mathrm{mm}^{3}$ ) and a more inclusive definition (WHO stage 3/4 or CD4 cell count $<350$ cells $/ \mathrm{mm}^{3}$ ).

Results: A total of 10,137 HIV-infected individuals were included in the analysis. The median age was 40 years; $68 \%$ were female. A total of $45.9 \%$ or $47.5 \%$ of the patients were late presenters, depending on the definition used. The percentage of patients with late presentation (defined as WHO stage 3/4 or CD4 cell count $<350$ cells $/ \mathrm{mm}^{3}$ ) decreased during recent years, from $70.7 \%$ in 2013 to $46.5 \%$ in 2017 and $23.4 \%$ in 2020. Age was associated with a significantly higher risk of $L P(p<0.0001)$. We did not observe any impact of sex.

Conclusions: The frequency of late presentation for care is decreasing in Kinshasa, DRC. Efforts have to be continued. In particular, the issue of late diagnosis in older individuals should be addressed.
\end{abstract}

Keywords: Late presentation, HIV care, Kinshasa

\section{Introduction}

Antiretroviral therapy (ART) represents a remarkable success in recent medicine. ART radically decreases the morbidity and mortality of human immunodeficiency virus (HIV)-infected individuals and drastically reduces the risk of HIV transmission $[1,2]$.

\footnotetext{
*Correspondence: nadiamayas02@gmail.com; gdarcis@chuliege.be ${ }^{1}$ Department of Internal Medicine, Infectious and Tropical Diseases, University Clinics of Kinshasa, Kinshasa, Democratic Republic of the Congo

${ }^{3}$ Department of Internal Medicine and Infectious Diseases, Liège University Hospital, Liège, Belgium

Full list of author information is available at the end of the article
}

The development of effective and less toxic medications led to guideline modifications culminating in 2015 with the adoption of the "treat all" strategy. For the first time, the WHO guidelines recommended that ART should be initiated in everyone living with HIV with any CD4 cell count [3]. The 2017 consolidated guidelines stated that ART initiation should be offered on the same day to people who are ready to start, with the worthy objective of improving the scaling up of ART [4].

The implementation of the WHO and national guidelines led to a significant decrease in time from diagnosis to treatment initiation, as shown in multiple studies in Sub-Saharan Africa [5-7]. Although this observation 
shows the success of the treat all strategy implementation, it should not mask the fact that many other hurdles remain to reach better ART coverage.

By the end of 2019, it was estimated that $67 \%$ of people living with HIV worldwide were on ART [8]. In Africa, this number reached $70 \%$ [8]. The numbers are increasing over time. Nevertheless, many infected individuals still ignore their status. Among them, many will likely present for care later in the course of the infection.

Indeed, late presentation (LP) for care is a welldescribed, persistent issue for the success of ART outcomes. Late presenters suffer from a higher morbidity and mortality and from a poorer immune recovery [9, 10]. Late presenters can also transmit HIV during a prolonged period. Moreover, LP could be associated with a higher chance of attrition from care during follow-up [11]. From a cure perspective, it is well established that early ART initiation is associated with an HIV latent reservoir of smaller size and reduced diversity, a phenotype that would favor several cure strategies [12,13].

Despite its recognized negative impact on the HIV epidemic, late presentation for care remains a too-common concern in many regions worldwide [14-19]. Various strategies can be used to mitigate the LP issue, including information campaigns, HIV screening promotion, and combating stigma and discrimination.

Understanding the factors associated with late presentation in a local context would help to tailor screening/ information strategies for better efficiency.

Here, we studied the frequency of LP over time in Kinshasa, Democratic Republic of Congo (DRC). We also performed an analysis of the factors associated with LP with the goal of refining local screening policies.

\section{Material and methods}

\section{Study design and analysis}

This was a retrospective cohort study in Kinshasa, the capital of the DRC. The studied population included HIV-positive adults ( $\geq 16$ years) newly enrolled in HIV care between January 2006 and June 2020 at 25 HIV urban care facilities. The participating facilities are part of national ART programs, and the provision of services at each facility was conducted according to the guidelines of the Congolese Ministry of Health and the WHO. Patient information routinely collected at presentation for HIV care included age, sex, WHO clinical stage and screening context. Regarding the screening context, HIV diagnosis was made either at Kalembe Lembe Pediatric Hospital (KLL, services to $\mathrm{HIV}^{+}$children and their first-line family members) or at various centers related to the International Centre for Aids Care and Treatment Programs (ICAP). As children were not included in the analysis, only family members diagnosed at KLL were included.

We used two definitions of late presentation:

- The WHO definition of advanced HIV disease: a CD4 cell count of $<200$ cells $/ \mathrm{mm}^{3}$ or a WHO clinical stage 3 or 4 event at presentation for care [4],

- A more inclusive and widely used definition in the literature $[19,20]:<350$ cells $/ \mathrm{mm}^{3}$ or a WHO clinical stage 3 or 4 event at presentation for care.

We defined CD4 count testing at presentation as having a CD4 cell count performed up to 3 months following HIV diagnosis.

The data for this study were collected either directly from the standard patient medical records or from the electronic databases, depending on the facility. Data quality assessments were performed every 6 months to assess the completeness and accuracy of data entry. The Ethical Committee of the School of Public Health, University of Kinshasa approved the use of data for this study.

\section{Statistical analysis}

Quantitative variables are summarized as the mean and standard deviation (SD) or median and interquartile range (IQR: p25-p75). Categorical variables are presented as frequency tables (numbers and percentages). The impact of time (year of HIV diagnosis) and other factors on baseline $\mathrm{CD} 4$ count testing were analyzed using logistic regression models. No missing data was replaced. The results were considered significant at the uncertainty level of $5 \%(\mathrm{p}<0.05)$. The statistical analyses were performed using SAS software (version 9.4), and the graphics were made using $\mathrm{R}$ software (version 3.6.1).

\section{Results}

A total of 10,137 HIV-infected individuals were included in the analysis (Table 1). The median age was 40 years, $68 \%$ were female, and $91 \%$ were married. The median body mass index (BMI) was 21.9. The majority of HIV diagnoses were made at ICAP centers (89\%). The number of days between diagnosis and initial CD4 cell count was short (mean \pm SD: $1.6 \pm 14.8$ ).

As indicated in Table 2, $45.9 \%$ or $47.5 \%$ of the patients were late presenters, depending on the definition used. The difference between definitions is slight because the numbers were mainly influenced by WHO stages. Indeed, CD4 cell counts at baseline were rarely performed in the DRC and have been totally abandoned in recent years [21].

It should be noted that the percentage of LP has decreased over time, particularly in recent years. We observed a drop from $70.7 \%$ in 2013 to $46.5 \%$ in 2017 , 
Table 1 Characteristics of $\mathrm{HIV}^{+}$individuals at time of HIV diagnosis ( $\left.\mathrm{N}=10137\right)$

\begin{tabular}{|c|c|c|c|c|}
\hline & N (\%) & Mean \pm SD & Median (IQR) & Extremes \\
\hline Age (years) & 10137 & $39.9 \pm 11.0$ & $40(32 ; 47)$ & $16-88$ \\
\hline Sex (female) & 6925/10137 (68.3) & & & \\
\hline Height (cm) & 1197 & $163 \pm 8$ & $163(158 ; 168)$ & 126-195 \\
\hline Weight (kg) & 8762 & $60.0 \pm 12.2$ & $59(52 ; 66)$ & $30-120$ \\
\hline $\mathrm{BMI}\left(\mathrm{kg} / \mathrm{m}^{2}\right)$ & 1197 & $22.6 \pm 4.4$ & $21.9(19.6 ; 25.1)$ & $11.2-42.7$ \\
\hline Married & 499/547 (91.2) & & & \\
\hline \multicolumn{5}{|l|}{ Year of diagnosis } \\
\hline 2006 & 95/10137 (1.0) & & & \\
\hline 2007 & 103/10137 (1.0) & & & \\
\hline 2008 & 101/10137 (1.0) & & & \\
\hline 2009 & 192/10137 (1.9) & & & \\
\hline 2010 & 246/10137 (2.4) & & & \\
\hline 2011 & $311 / 10137(3.1)$ & & & \\
\hline 2012 & 419/10137 (4.1) & & & \\
\hline 2013 & $576 / 10137(5.7)$ & & & \\
\hline 2014 & 717/10137 (7.1) & & & \\
\hline 2015 & 705/10137 (7.0) & & & \\
\hline 2016 & $907 / 10137(9.0)$ & & & \\
\hline 2017 & 1179/10137 (11.6) & & & \\
\hline 2018 & 1951/10137 (19.3) & & & \\
\hline 2019 & 1955/10137 (19.3) & & & \\
\hline 2020 & $680 / 10137(6.7)$ & & & \\
\hline \multicolumn{5}{|l|}{ Context of screening } \\
\hline Kalembe Lembe Pediatric Hospital (KLL) & 1099/10137 (10.8) & & & \\
\hline $\begin{array}{l}\text { International Centre for Aids Care and Treatment } \\
\text { Programs (ICAP) }\end{array}$ & $9038 / 10137(89.2)$ & & & \\
\hline
\end{tabular}

Table 2 Numbers and percentages of LP over time

\begin{tabular}{lrcc}
\hline & N & $\begin{array}{l}\text { CD4 }<200 / \mathbf{m m}^{3} \\
\text { or WHO 3 or 4 }\end{array}$ & $\begin{array}{l}\text { CD4 }<350 / \mathbf{m m}^{3} \\
\text { or WHO 3 or 4 }\end{array}$ \\
\hline \multicolumn{2}{r}{ Year of diagnosis } & & $71(75.5)$ \\
2006 & 94 & $67(71.3)$ & $69(74.2)$ \\
2007 & 93 & $66(71.0)$ & $64(67.4)$ \\
2008 & 95 & $58(61.0)$ & $97(53.9)$ \\
2009 & 180 & $88(48.9)$ & $143(60.1)$ \\
2010 & 238 & $125(52.5)$ & $196(65.1)$ \\
2011 & 301 & $181(60.1)$ & $262(65.0)$ \\
2012 & 403 & $244(60.6)$ & $389(70.7)$ \\
2013 & 550 & $373(67.8)$ & $467(67.9)$ \\
2014 & 688 & $449(65.3)$ & $462(67.5)$ \\
2015 & 684 & $434(63.4)$ & $519(60.7)$ \\
2016 & 855 & $496(58.0)$ & $531(46.5)$ \\
2017 & 1141 & $529(46.4)$ & $760(39.4)$ \\
2018 & 1927 & $760(39.4)$ & $498(25.6)$ \\
2019 & 1944 & $498(25.6)$ & $156(23.4)$ \\
2020 & 667 & $156(23.4)$ & $\mathbf{4 6 8 4}(\mathbf{4 7 . 5})$ \\
All & $\mathbf{9 8 6 0}$ & $\mathbf{4 5 2 4 ( 4 5 . 9 )}$ &
\end{tabular}

$25.6 \%$ in 2019 and $23.4 \%$ in 2020 ; late presentation was defined as $<350$ cells $/ \mathrm{mm}^{3}$ or a WHO clinical stage 3 or 4 event at presentation for care (Table 2, Fig. 1).

\section{Factors independently associated with late presentation}

The impacts of time (year of HIV diagnosis) and other factors on the probability of late presentation were analyzed using multiple logistic regression models. Table 3 presents the adjusted odds ratios of being a late presenter depending on the LP definition. Age was associated with a significantly higher risk of being a late presenter $(\mathrm{p}<0.0001)$. The percentage of LP decreased over time $(\mathrm{p}<0.0001)$. It should be noted that the probability of being a late presenter increased when a CD4 cell count at baseline was performed. This could be an important confounding factor in our analysis, as CD4 cell count measurement at baseline has been abandoned in recent years [21]. However, the percentage of LP based on a pure clinical definition also significantly decreased over time (Fig. 1, Table 3). Table 3 indeed shows that the risk of being a late presenter decreased over time when considering a pure clinical definition (OR: 0.79 (0.78-0.81); 


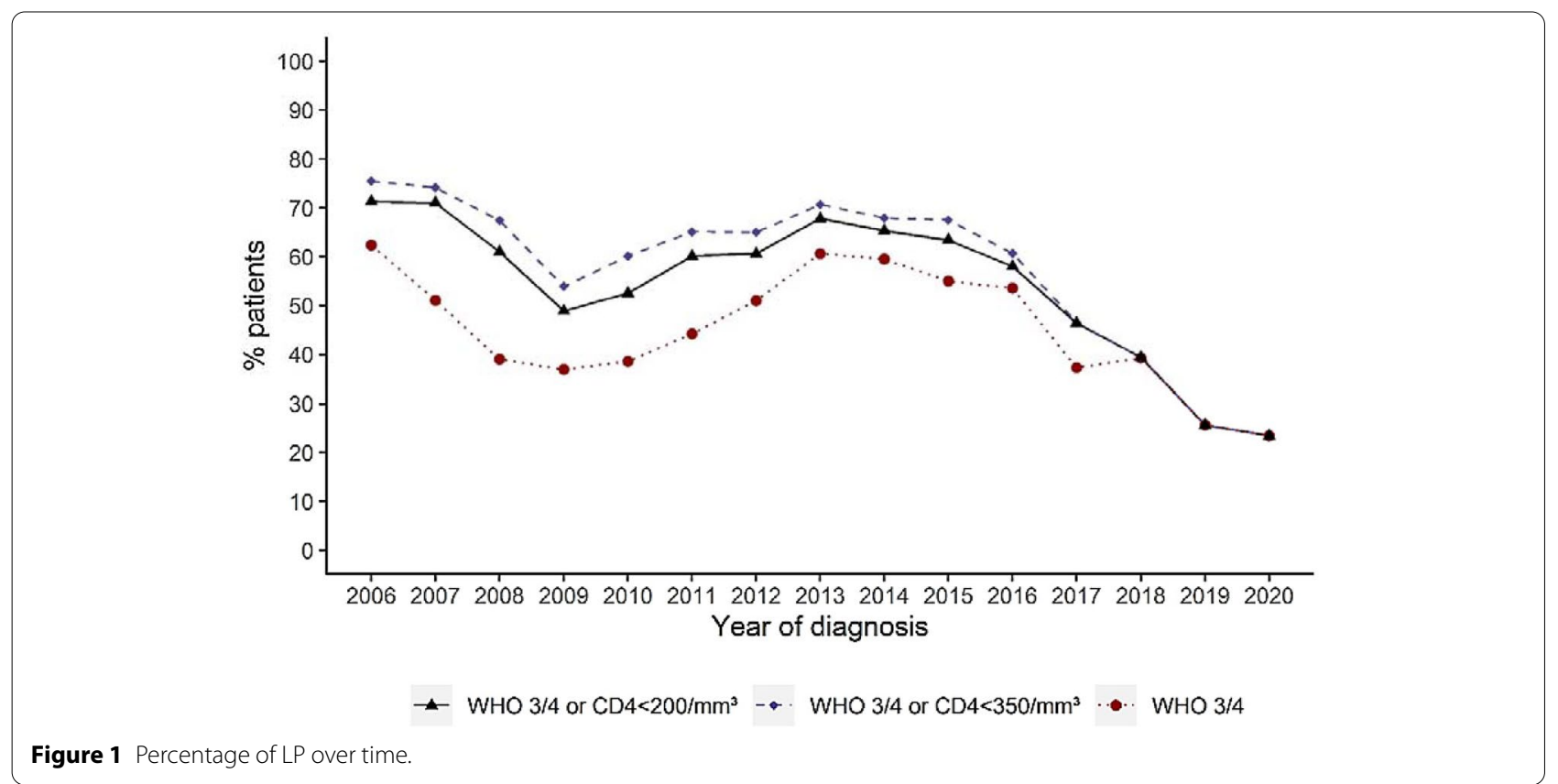

Table 3 Factors associated with late presentation-Multiple logistic regression model $(N=9860)$

\begin{tabular}{|c|c|c|c|c|}
\hline & Variables & Coefficient \pm SE & OR $(95 \% \mathrm{Cl})$ & p-value \\
\hline Probability of late & Intercept & $0.058 \pm 0.13$ & - & - \\
\hline presentation $\left(C D 4<200 / \mathrm{mm}^{3}\right.$ & Age (by 10 years older) & $0.22 \pm 0.020$ & $1.2(1.2-1.3)$ & $<0.0001$ \\
\hline \multirow[t]{4}{*}{ or WHO 3 or 4) } & Sex (ref = male) & $-0.0085 \pm 0.024$ & $0.98(0.90-1.1)$ & 0.72 \\
\hline & Year of HIV diagnosis (by year from 2006) & $-0.20 \pm 0.010$ & $0.82(0.80-0.84)$ & $<0.0001$ \\
\hline & Context of screening $(r e f=$ pediatric center $\mathrm{KLL})$ & $0.86 \pm 0.045$ & $5.6(4.7-6.7)$ & $<0.0001$ \\
\hline & Presence of CD4 measurement $(r e f=$ No) & $0.86 \pm 0.066$ & $2.4(2.1-2.7)$ & $<0.0001$ \\
\hline Probability of late & Intercept & $0.063 \pm 0.13$ & - & - \\
\hline presentation $\left(C D 4<350 / \mathrm{mm}^{3}\right.$ & Age (by 10 years older) & $0.22 \pm 0.021$ & $1.3(1.2-1.3)$ & $<0.0001$ \\
\hline \multirow[t]{4}{*}{ or WHO 3 or 4$)$} & Sex (ref = male) & $-0.0087 \pm 0.024$ & $0.98(0.89-1.1)$ & 0.72 \\
\hline & Year of HIV diagnosis (by year from 2006) & $-0.20 \pm 0.010$ & $0.82(0.80-0.84)$ & $<0.0001$ \\
\hline & Context of screening $(r e f=$ pediatric center $\mathrm{KL} L)$ & $0.82 \pm 0.046$ & $5.2(4.3-6.2)$ & $<0.0001$ \\
\hline & Presence of $\mathrm{CD} 4$ measurement $(\mathrm{ref}=\mathrm{No})$ & $1.1 \pm 0.069$ & $3.1(2.7-3.5)$ & $<0.0001$ \\
\hline Probability of late & Intercept & $0.35 \pm 0.11$ & - & - \\
\hline \multirow[t]{4}{*}{ presentation (WHO 3 or 4) } & Age (by 10 years older) & $0.22 \pm 0.020$ & $1.2(1.2-1.3)$ & $<0.0001$ \\
\hline & Sex (ref = male) & $-0.0057 \pm 0.024$ & $0.99(0.90-1.1)$ & 0.81 \\
\hline & Year of HIV diagnosis (by year from 2006) & $-0.23 \pm 0.0091$ & $0.79(0.78-0.81)$ & $<0.0001$ \\
\hline & Context of screening $(r e f=$ pediatric center $\mathrm{KLL})$ & $1.1 \pm 0.049$ & $8.3(6.9-10.1)$ & $<0.0001$ \\
\hline
\end{tabular}

$\mathrm{p}<0.0001)$. The decrease in HIV diagnosis at a late clinical stage is also illustrated in Fig. 1.

In particular, the level of $\mathrm{HIV}^{+}$individuals at WHO stage 1 radically increased over time, while the percentages of individuals diagnosed at later clinical stages (WHO 3 or 4) significantly decreased (Table 4). We did not observe any impact of sex on LP. In contrast, we showed an important impact of the type of center where HIV screening was offered, KLL vs ICAP. This was not unexpected, as screening at KLL is mostly performed on a systematic basis and largely targets asymptomatic individuals. 
Table 4 WHO stage at HIV diagnosis

\begin{tabular}{|c|c|c|c|c|c|c|}
\hline \multirow[t]{2}{*}{ Year of diagnosis } & \multirow[t]{2}{*}{$\mathrm{N}$} & \multicolumn{4}{|l|}{ WHO Stage } & \multirow[b]{2}{*}{4} \\
\hline & & Non-missing $n(\%)$ & 1 & 2 & 3 & \\
\hline 2006 & 95 & $93(97.9)$ & $15(16.1)$ & $20(21.5)$ & $49(52.7)$ & $9(9.7)$ \\
\hline 2007 & 103 & $90(87.4)$ & $16(17.8)$ & $28(31.1)$ & $39(43.3)$ & $7(7.8)$ \\
\hline 2008 & 101 & $95(94.1)$ & $38(40.0)$ & $20(21.0)$ & $30(31.6)$ & $7(7.4)$ \\
\hline 2009 & 192 & $179(93.2)$ & $85(47.5)$ & $28(15.6)$ & $62(34.6)$ & $4(2.2)$ \\
\hline 2010 & 246 & $223(90.6)$ & $97(43.5)$ & $40(17.9)$ & $73(32.7)$ & $13(5.8)$ \\
\hline 2011 & 311 & $292(93.9)$ & $109(37.3)$ & $54(18.5)$ & $116(39.7)$ & $13(4.4)$ \\
\hline 2012 & 419 & $380(90.7)$ & $128(33.7)$ & $58(15.3)$ & $168(44.2)$ & $26(6.8)$ \\
\hline 2013 & 576 & $535(92.9)$ & $101(18.9)$ & $110(20.6)$ & $288(53.8)$ & $36(6.7)$ \\
\hline 2014 & 717 & $669(93.3)$ & $164(24.5)$ & $107(16.0)$ & $365(54.6)$ & $33(4.9)$ \\
\hline 2015 & 705 & $675(95.7)$ & $154(22.8)$ & $150(22.2)$ & $333(49.3)$ & $38(5.6)$ \\
\hline 2016 & 907 & 849 (93.6) & $224(26.4)$ & $170(20.0)$ & $408(48.1)$ & $47(5.5)$ \\
\hline 2017 & 1179 & $1141(96.8)$ & $337(29.5)$ & $278(24.4)$ & $450(39.4)$ & $76(6.7)$ \\
\hline 2018 & 1951 & 1927 (98.8) & $668(34.7)$ & $501(26.0)$ & $670(34.8)$ & $88(4.6)$ \\
\hline 2019 & 1955 & $1944(99.4)$ & $791(40.7)$ & $655(33.7)$ & $450(23.1)$ & $48(2.5)$ \\
\hline 2020 & 680 & $667(98.1)$ & $317(47.5)$ & $194(29.1)$ & $141(21.1)$ & $15(2.2)$ \\
\hline All & 10137 & 9759 (96.3) & $3244(33.2)$ & $2413(24.7)$ & $3642(37.3)$ & $460(4.7)$ \\
\hline
\end{tabular}

\section{Discussion}

The development of effective and minimally toxic ART led to the adoption of the treat all strategy. The benefits of early ART have been strongly demonstrated at the individual and community levels. To reach the worthy objective of treating all HIV-infected individuals early, ART should be initiated soon after the diagnosis, as recommended. However, offering ART early during the course of the infection also requires early diagnosis.

Late presentation is indeed a persistent global concern. Factors associated with late presentation vary from one country to another and are affected by numerous factors, such as local epidemic features, the ability of information or screening campaigns to reach specific subgroups, the availability and cost of screening tests, and the capacity of healthcare providers to identify the first signs of the disease. A significant association between perceived HIV-related stigma and late presentation for HIV/AIDS care in low- and middle-income countries has also been demonstrated [22].

In this context, analyzing the prevalence and causes of delayed presentation for care is definitely of importance.

More than $10,000 \mathrm{HIV}^{+}$individuals were included in our study. The level of late presentation was high, approximately $45 \%$, and comparable to percentages in other countries $[14,19,23]$. It should be noted that this number is likely underestimated, as CD4 cell count at baseline was rarely performed in the DRC, particularly during recent years [21].
Although the mean percentage of LP was high, we showed an encouraging, strong and persistent diminution of LP over time. The impact of the phasing out of CD4 cell count measurement seems minimal, as the percentage of LP similarly decreased when considering only clinical stages. The reduction of LP over time is thus related to an earlier identification of $\mathrm{HIV}^{+}$individuals. A similar diminution of LP in recent years has been observed in Georgia [24]. Interestingly, the decline in late presentation was thought to be associated with improving HIV testing services in the country, but it was also associated with an increased incidence of HIV infection among men who have sex with men (MSM) diagnosed early, showing that the local evolution of the epidemic can impact LP [24].

We showed that the risk of being a late presenter increases with age. Older individuals have been repeatedly identified as a subgroup at risk for LP [14]. Healthcare providers may indeed consider HIV testing less often in individuals who are not perceived as being at high risk of HIV, such as older individuals. This is particularly harmful for older individuals, as they would benefit the most from fast ART initiation [25].

The comparison between the two types of screening centers is also very informative. The pediatric center proposes systematic HIV screening in children and relatives in various clinical contexts, including tuberculosis, hospitalizations, visits to hospital emergency services, and sexual abuse. Our study shows the benefit of this systematic HIV screening. The risk of being a 
late presenter did not differ between males and females. Several socioeconomic factors have previously been shown to be associated with LP $[19,26]$. However, we were not able to analyze such factors.

In conclusion, our work emphasized that the frequency of LP for care is decreasing in Kinshasa, DRC. Our results could likely be extended to other countries in sub-Saharan Africa where similar screening strategies and information campaigns have been performed. Efforts have to be continued and strengthened to reach lower numbers. In particular, information and screening approaches should target specific subgroups, such as older individuals. Voluntary testing should be encouraged through education campaigns targeting neglected groups with a higher risk of LP. More comprehensive data at diagnosis would be helpful in deciphering factors associated with LP. Data should ideally systematically address the reasons for delayed diagnosis. This will hopefully result in a lower rate of LP and ultimately in better treatment outcomes as well as reduced HIV transmission.

\section{Acknowledgments}

We thank all patients and staff at the HIV care and facilities included in these analyses.

\section{Authors' contributions}

NMN, HSN, MMM, MLM, BBI and FKN designed the work and acquired the data. NMN, NM, MM and GD analyzed the data. NMN and GD wrote the manuscript. All authors have read and approved the final manuscript.

\section{Funding}

This study was supported by the Léon Fredericq Foundation.

\section{Availability of data and material}

All data are presented in the manuscript.

\section{Code availability}

Not applicable.

\section{Declarations}

Ethics approval and consent to participate

The Ethical Committee of the School of Public Health, University of Kinshasa approved the use of data for this study. No informed consent was required for this retrospective analysis, according to The Ethical Committee of the School of Public Health, University of Kinshasa.

\section{Consent for publication}

Not applicable.

\section{Competing interests}

The authors declare no conflicts of interest.

\section{Author details}

${ }^{1}$ Department of Internal Medicine, Infectious and Tropical Diseases, University Clinics of Kinshasa, Kinshasa, Democratic Republic of the Congo. ${ }^{2}$ Biostatistics and Medico-economic Information Department, University Hospital of Liege, Liège, Belgium. ${ }^{3}$ Department of Internal Medicine and Infectious Diseases, Liège University Hospital, Liège, Belgium. ${ }^{4}$ AIDS reference laboratory, University of Liège, Liège, Belgium.
Received: 20 April 2021 Accepted: 7 July 2021

Published online: 16 July 2021

\section{References}

1. Rodger AJ, et al. Risk of HIV transmission through condomless sex in serodifferent gay couples with the HIV-positive partner taking suppressive antiretroviral therapy (PARTNER): final results of a multicentre, prospective, observational study. Lancet. 2019;393:2428-38.

2. Darcis G, Berkhout B, Pasternak AO. Differences in HIV markers between infected individuals treated with different ART regimens: implications for the persistence of viral reservoirs. Viruses. 2020. https://doi.org/10.3390/ v12050489.

3. World Health Organization, World Health Organization, \& Department of HIV/AIDS. Guideline on when to start antiretroviral therapy and on pre-exposure prophylaxis for HIV; 2015. http://apps.who.int/iris/bitst ream/handle/10665/186275/9789241509565_eng.pdf;jsessionid=8D92E 5DD362283D7376E4440F782540E? sequence=1. Accessed 31 Mar 2021.

4. World Health Organization. Guidelines for managing advanced HIV disease and rapid initiation of antiretroviral therapy; 2017. https://apps.who. int/iris/bitstream/handle/10665/255884/9789241550062-eng.pdf?seque nce $=1$. Accessed 31 Mar 2021.

5. Blaizot $\mathrm{S}$, et al. Potential impact of multiple interventions on HIV incidence in a hyperendemic region in Western Kenya: a modelling study. Dis BMC Infect. 2016. https://doi.org/10.1186/s12879-016-1520-4.

6. Blankley S, et al. Lessons learned: Retrospective assessment of outcomes and management of patients with advanced HIV disease in a semi-urban polyclinic in Epworth, Zimbabwe. PLOS One. 2019;14:e0214739.

7. Silverman RA, et al. Predictors of mortality within the first year of initiating antiretroviral therapy in urban and rural Kenya: a prospective cohort study. PloS one. 2019. https://doi.org/10.1371/journal.pone.0223411.

8. Global AIDS Update. Seizing the moment, Tackling entrenched inequalities to end epidemics; 2020. https://www.unaids.org/en/resources/ documents/2020/global-aids-report. Accessed 31 Mar 2021.

9. Lundgren JD, et al. Initiation of antiretroviral therapy in early asymptomatic HIV infection. N Engl J Med. 2015;373:795-807.

10. Robbins GK, et al. Incomplete reconstitution of T cell subsets on combination antiretroviral therapy in the AIDS Clinical Trials Group protocol 384. Clin Infect Dis. 2009;48:350-61.

11. Lebelonyane R, et al. Advanced HIV disease in the Botswana combination prevention project: prevalence, risk factors, and outcomes. AIDS Lond Engl. 2020;34:2223-30.

12. Deng K, et al. Broad CTL response is required to clear latent HIV-1 due to dominance of escape mutations. Nature. 2015;517:381-5.

13. Ait-Ammar A, et al. Current status of latency reversing agents facing the heterogeneity of HIV-1 cellular and tissue reservoirs. Front Microbiol. 2020. https://doi.org/10.3389/fmicb.2019.03060.

14. Darcis $\mathrm{G}$, et al. Factors associated with late presentation for HIV care in a single Belgian reference center: 2006-2017. Sci Rep. 2018;8:8594.

15. Belay GM, Endalamaw A, Ayele AD. Late presentation of HIV positive adults and its predictors to HIV/AIDS care in Ethiopia: a systematic review and meta-analysis. BMC Infect Dis. 2019;19:534.

16. Komninakis SV, Mota ML, Hunter JR, Diaz RS. Late Presentation HIV/AIDS Is Still a Challenge in Brazil and Worldwide. AIDS Res Hum Retroviruses. 2018;34:129-31.

17. Wilton J, et al. Late diagnosis, delayed presentation and late presentation among persons enrolled in a clinical HIV cohort in Ontario, Canada (1999-2013). HIV Med. 2019;20:110-20.

18. Raffetti $E$, et al. The risk of late or advanced presentation of HIV infected patients is still high, associated factors evolve but impact on overall mortality is vanishing over calendar years: results from the Italian MASTER Cohort. BMC Public Health. 2016;16:878.

19. Late presenters working group in COHERE in EuroCoord, et al. Late presentation for HIV care across Europe: update from the Collaboration of Observational HIV Epidemiological Research Europe (COHERE) study. Euro Surveill Bull Eur Sur Mal Transm Eur Commun Dis Bull. 2015;20:30070

20. Antinori A, et al. Late presentation of HIV infection: a consensus definition. HIV Med. 2011;12:61-4. 
21. Ngongo NM, et al. Progressive phasing out of baseline CD4+ cell count testing for people living with HIV in Kinshasa, Democratic Republic of the Congo. AIDS Lond Engl. 2021;35:841-3.

22 Gesesew HA, et al. Significant association between perceived HIV related stigma and late presentation for HIV/AIDS care in low and middleincome countries: a systematic review and meta-analysis. PloS One. 2017;12:e0173928.

23. Darling KE, et al. Late presentation to HIV care despite good access to health services: current epidemiological trends and how to do better. Swiss Med Wkly. 2016;146:w14348.

24 Chkhartishvili N, et al. Late presentation of HIV infection in the country of Georgia: 2012-2015. PLoS One. 2017. https://doi.org/10.1371/journal. pone. 0186835 .
25. Molina J-M, et al. Which HIV-infected adults with high CD4 T-cell counts benefit most from immediate initiation of antiretroviral therapy? A posthoc subgroup analysis of the START trial. Lancet HIV. 2018;5:e172-80.

26. Abaynew Y, Deribew A, Deribe K. Factors associated with late presentation to HIV/AIDS care in South Wollo Zone Ethiopia: a case-control study. AIDS Res Ther. 2011;8:8.

\section{Publisher's Note}

Springer Nature remains neutral with regard to jurisdictional claims in published maps and institutional affiliations.
Ready to submit your research? Choose BMC and benefit from:

- fast, convenient online submission

- thorough peer review by experienced researchers in your field

- rapid publication on acceptance

- support for research data, including large and complex data types

- gold Open Access which fosters wider collaboration and increased citations

- maximum visibility for your research: over $100 \mathrm{M}$ website views per year

At BMC, research is always in progress.

Learn more biomedcentral.com/submissions 